\title{
Design of Meyer's Theory-based High Quality Piano Multi-media System
}

\author{
https://doi.org/10.3991/ijet.v12i01.6486 \\ Pengfei Li \\ Suzhou University, Suzhou, China \\ qqinyuan@yeah . net
}

\begin{abstract}
Based on the current situation of the development of multi-media technology and its application in colleges and universities, this paper selected high-quality multi-media hardware devices suitable for the piano curriculum, followed Meyer's principles for multi-media instruction design, and designed a multi-media through the visualization of multi-media information, promotion of necessary cognitive processing, reduction of external cognitive processing, stimulation of generative cognitive processing and other information processing methods, to improve the information presentation ways and delivery strategies for multi-media teaching software. To a certain extent, the system prevents teachers from neglecting learners' cognitive mechanism when processing information for their multi-media teaching software, and also improves the multimedia teaching effect of music-oriented courses, thereby having important guiding significance for multi-media teaching as well as the design and production of teaching software. Meanwhile, it provides theoretical and statistical support for the application of high-quality multi-media teaching system in musicoriented courses and college education.
\end{abstract}

Keywords-Meyer's theory, high-quality, teaching system, multi-media

\section{Introduction}

With the continuous development of Internet technology and multi-media technology, many people now can enjoy high-quality courses without leaving home. Even if they are not in the same classroom, they can hear the same course. Therefore, this way of education is favored by many students and teachers, and can greatly improve the effect and quality of teaching [1]. As a modern teaching method, multi-media technology has been introduced into the teaching of impromptu piano accompaniment, which is beneficial to the acquisition and maintenance of knowledge by students, as well as the enrichment of teaching content and improvement of teaching quality among teachers. However, the current situation is that the lack of teaching information design and the lack of considerations about meeting learners' psychological 
work mechanism occur in information processing by most teaching software. The purpose of multi-media teaching software is to promote and improve the effect of teaching and learning. Undoubtedly, wonderful teaching software can really improve the effect of teaching and learning, but teaching software designed irrationally will adversely inhibit the production of the expected teaching effect.

\section{Review of Research Progress}

Teachers and students can communicate and interact with each other through Internet technology and multi-media technology. However, for piano and some other music-oriented courses, the teaching effect is greatly reduced since audio technology and other multi-media technology are still under-developed [2]. Therefore, the development of audio and video technology to improve the integration of multi-media technology is the development trend and demand in modern education [3]. Costantini et al. put forward an audio transcription system. The proposed method in concentrated on temporal musical structures, note events and their primary features: the pitch and the attack instant. The system has been tested and found to have sound results [4]. Cui Qing studied four teaching methods of piano digitalization in the network environment, analyzed the composition of digital piano software and hardware system, multimedia projection and the overall structure of teaching in LAN, designed the multimedia network classroom, and proved that its application in piano teaching can improve the teaching performance [5]. Some researchers used partial functions of the computer music software SONAR 8 and applied it to the teaching of music notation. Through the application, the researchers found that the system can assist students to have auditory perception in addition to the traditional visual perception, so as they can better understand and grasp the music rhythm [6].

Currently, audio technology, as the most expressive media in multi-media technology, has a positive effect on improving teaching efficiency. For instance, for the teaching of piano, especially relevant theoretical knowledge, PPT courseware enables students to apprehend the content of teaching at a glance and reduce the pressure on teachers in the process of preparation, achieving good results. Nevertheless, the use of audio technology in multi-media teaching has many shortcomings: (1) the problem of audio equipment connection: In the connection of traditional audio equipment, it is a common practice to connect the music source generator, such as the computer, MP3 and other equipment in the classroom with the audio equipment in the wired manner. It is relatively inconvenient for the user to upload the music to the audio equipment; in addition, the wired connection between devices within the audio system and the speaker, such as connection between the amplifier and the speaker, or connection between active speakers, would make it extremely inconvenient to use equipment in practical teaching and is not conducive to teaching piano [9]. (2) The problem of audio fidelity: Apart from the wired connection between some audio equipment, some devices may be connected in other ways. For example, the sound generator and the speaker are connected through Bluetooth wirelessly, but Bluetooth is likely to negatively influence transmission and sound quality. Even the use of traditional connec- 
tions will lead to unstable sound, incomplete music form, audio distortion, etc. [10]. (3) The problem concerning bandwidth and real-time transmission of the audio receiver: The bandwidth of the audio receiver determines whether the user can get highquality audio and corresponding music data. Wider bandwidth generally brings easier access to more high-quality music. Another problem is about real-time transmission. In addition to distance teaching which has a high requirement on real-time transmission, ladder classrooms and large classrooms in some colleges and universities now also need real-time audio transmission, so that teachers can have better communication with students and lead students to understand the teaching content.

Therefore, according to research on the current situation, this paper constructed a high-quality multi-media audio teaching system based on Meyer's theory. The system is innovative in the following aspects: (1) the music box in the teaching system is connected to each speaker through special digital wireless communication, so that all speakers are fully synchronized and less vulnerable to interference from external wireless signals; (2) secondly, the high-quality multi-media system comprises a music box and at least one speaker, wherein the music box and each speaker are connected with each other through special digital wireless communication, so as to guarantee sound quality. This paper reported the generation and architecture of the high-quality multi-media teaching system in the course of piano, to provide reference for other multi-media teaching, music-oriented teaching and the teaching that requires the use of a multi-media system.

\section{Theoretical Basis}

\subsection{Meyer's processing method to achieve information visualization in multi- media teaching software}

"Meyer's theory" believes that the essential characteristic of multi-media is its simultaneous inclusion of both texts and pictures [11]. Meyer employed the information processing approach to analyze dual coding and proposed multi-media learning model. It contains not only written text, but also verbal text, that is, the teacher's speech and the voice dubbed in the multi-media teaching software. Pictures refer to images, consisting of static images and dynamic images. The former cover lustrations, charts, maps, brief strokes, photos and images produced by a variety of graphics software. The latter include animations, video clips, and so on. When the visual and auditory perception work on human organs at the same time, visual information will be encoded by the image system and textual information will be encoded by the language system. Meanwhile, information in the image memory area also leaves the corresponding mark in the language memory area. Since information resides in the two memory areas simultaneously and is encoded in two ways, two clues are provided for recall. Thus, "text + image" information processing is conducive to the understanding of knowledge and the memorization of knowledge. 


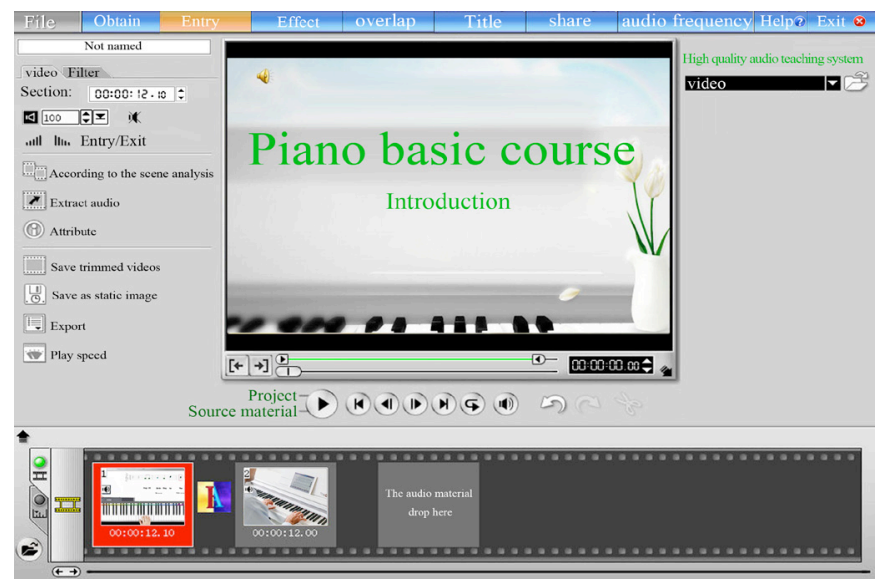

Fig. 1. Visualization strategy of piano multi-media course

Figure 1 shows a visualization strategy for a knowledge point in the piano course. In the production of teaching software, processing and handling of corresponding knowledge, coordinating with explanation by the teacher or dubbed explanation in the video, can achieve the effect of double coding to deepen students' understanding and memorization of knowledge.

\subsection{Cognitive load framework of Meyer's theory}

Specifically, Meyer's theory holds that in the three cognitive processes corresponding to cognitive needs, there are three cognitive loads for multi-media learning, namely, necessary processing, incidental processing and maintenance of superficial characteristics [12]. Subsequently, after several revisions and redefinitions, the three types of cognitive load mentioned above have gradually evolved into the cognitive processing framework that maps to the three types of cognitive load in cognitive load theory, namely, necessary processing, external processing and generation processing, and thereby constituted Meyer's cognitive load ternary model of multi-media learning.

\section{Development and Implementation of the High-quality Multi- media Teaching System}

\subsection{Logical structure of the system database}

Logical structure of the system database was analyzed respectively from three aspects, including student information, video library information and audio equipment 
information (as shown in Table 1: student and video library information table, and Table 2: audio equipment information table).

\subsection{Technical program of the system hardware}

As for the design of the high-quality multi-media teaching system which will be applied in the teaching of piano or other forms of music, the technical experimental program of the system's hardware part covers three types, including ordinary wired audio system, wireless Bluetooth audio system, and completely wireless high-quality audio system.

(1) Ordinary wired audio system. Similar to the music source generator, such as CD, DVD, MP3, TV and the speaker which are connected in the wired way, components within the audio system are connected to the speaker in the wired manner. This audio system is the most widely used, due to its relatively low price. However, it has some obvious shortcomings. For example, it is extremely inconvenient for the user to upload the music to the speaker. In addition, wired connection usually affects the appearance, increases the complexity, and brings inconvenience in use.

(2) Wireless Bluetooth audio system. In this system, the music source generator and the speaker is connected via wireless Bluetooth. This audio system casts off wired connection, but Bluetooth is not conductive to transmission and would impact the sound quality. In addition, Bluetooth is featured by a small control range and the lack of mobility.

(3) Completely wireless high-quality audio system. The system comprises a music box and at least one speaker. The music box is connected with speaker through the special digital wireless communication way to form one-to-many wireless output. This system accesses to music signals through wireless WiFi. Undoubtedly, wireless connection is easy to use, does not affect the sound quality, enables all speakers to be fully synchronized, is less susceptible to external wireless signal interference, and can realize output of a variety of musical forms through combining speakers, such as stereo from 2.0 channel, 5.1 (center channel, front left and right channels, rear left and right surrounding channels), and 7.1 (surrounding sound is added to 5.1 main speaker and rear surrounding speaker). Its disadvantage lies in the narrow range of implementation. The system structure is shown in Figure 2.

To better solve the current audio technology problem in piano teaching and improve the high-quality multi-media teaching system, this paper selected the completely wireless high-quality audio system. In specific implementation, the wireless audio receiver receives the first audio signal through the first receiving antenna, meaning that the music source is obtained through wireless WiFi. Then, the music box sends the received audio signal to the speaker through the wireless communication connection, greatly enhancing the user's convenience and the system's mobile performance. Notably, the speaker further comprises a micro-processor which is respectively connected to the second audio transmitter, the power amplifier and so on. As an important part of the system, the music box and speaker have their own structure, respectively shown in Figure 3 and Figure 4. 
Paper-Design of Meyer's Theory-based High Quality Piano Multi-media System

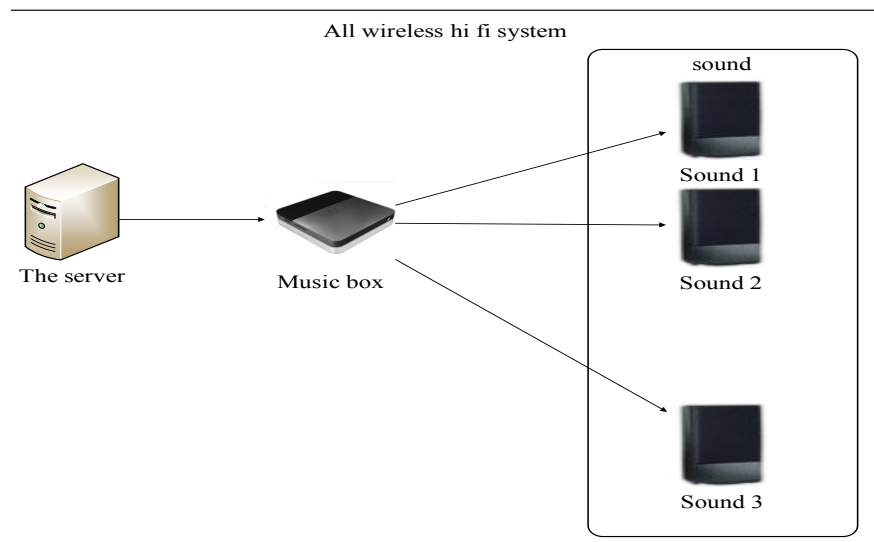

Fig. 2. Structure of completely wireless high-quality audio system

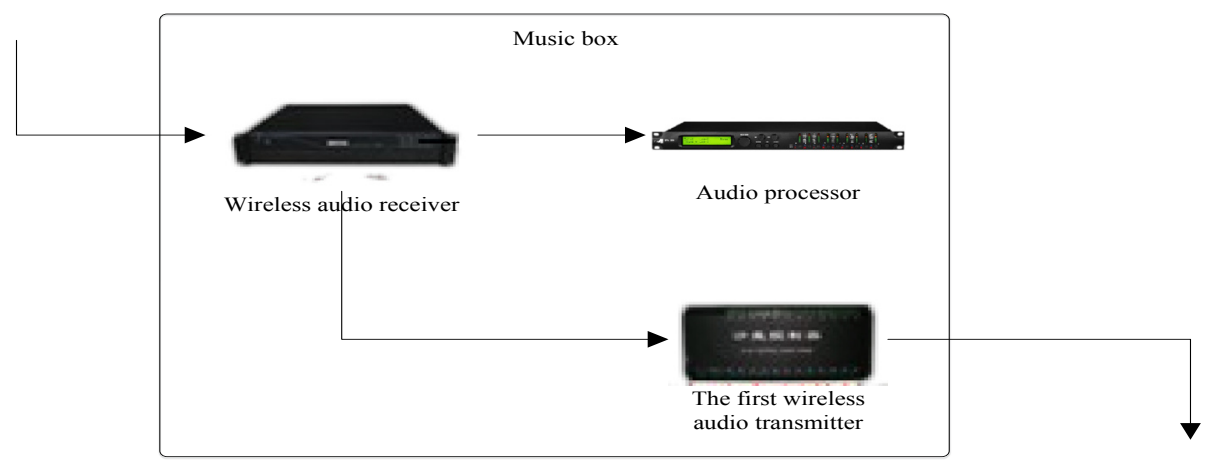

Fig. 3. Structure of the music box

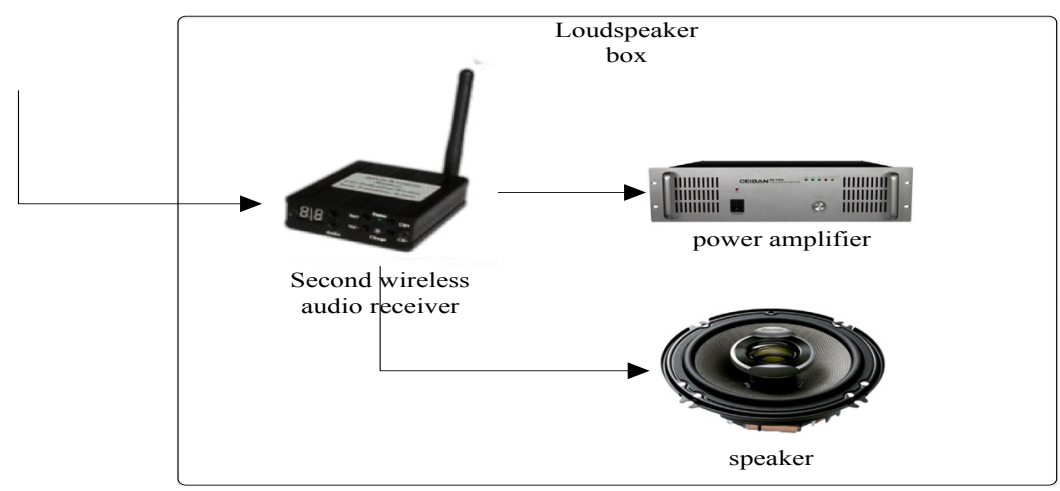

Fig. 4. Structure of the speaker 


\subsection{Development and implementation of the system}

As JAVA technology has several characteristics including simple cross-platform operation, strong portability, and impressive concurrency, the high-quality multimedia teaching system can be developed through JAVA technology. In particular, JavaApplet technology could be used to achieve dynamic client-side interface. The combination of HTTP protocol tunnel and server-side Servlet communication with a scientific evaluation model and overall dynamic programming will achieve interactive, personalized teaching.

In the high-quality multi-media teaching system, the three-tier Browser/WebServer/DataBaseServer system model is adopted. The front end provides students with a learning platform in the form of browser, but JavaApplet is embedded in the page for interactive and dynamic display; JSP/Servlet server is used at the rear end. Applet downloads courseware script from the server, plays it, and is responsible for communication with server-side Servlet. The specific configuration is: Windows98+InternetExplorer6.0 are installed at the client side.

Windows2000Server+ApacheServer2.0+JakartaTomcat4.0 are installed at the server side, while the database server uses MicrosoftSQLServer2000. In addition, the client and server side also need to install Java runtime JRE1.3. The system's structure is shown in Figure 5.

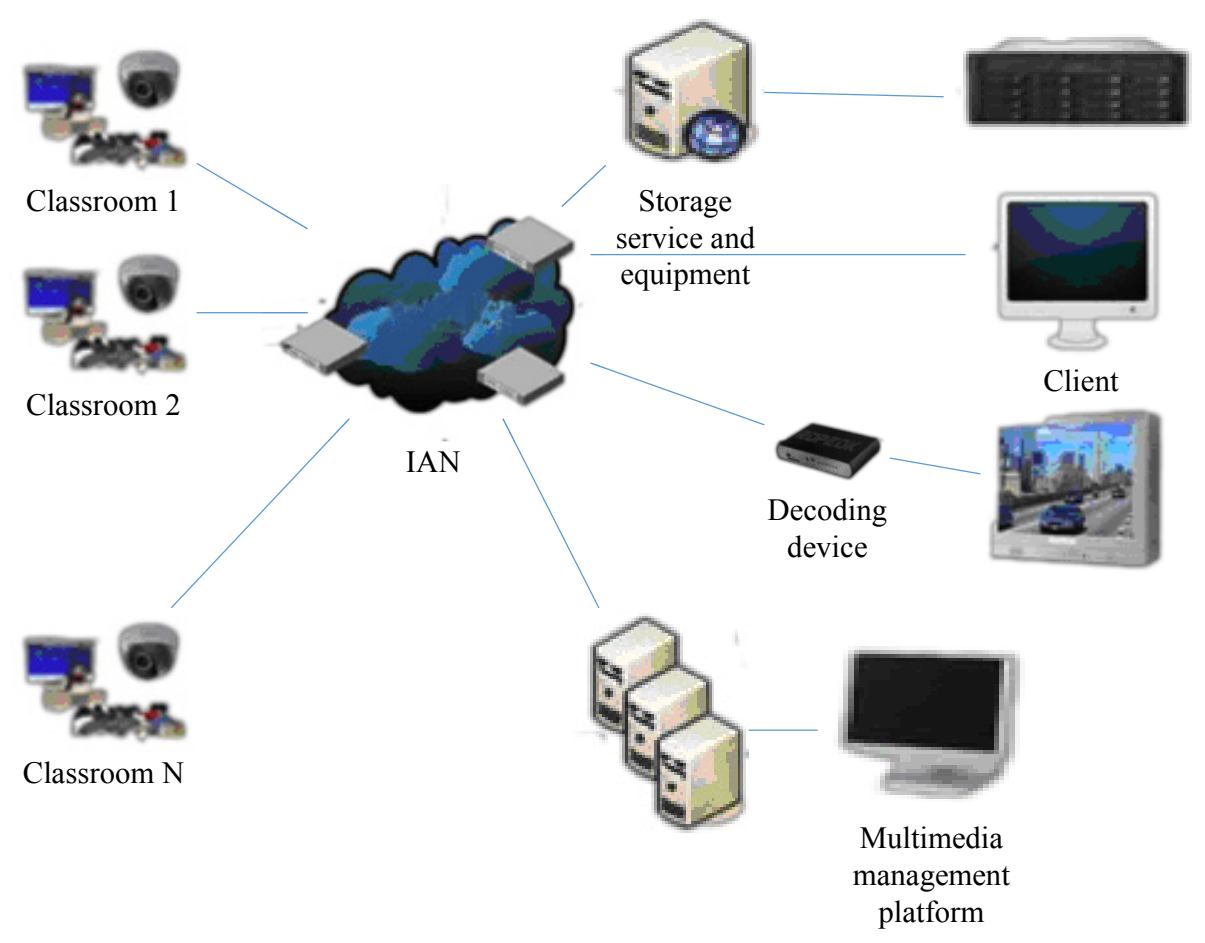

Fig. 5. Structure of the system 


\section{Module Structure of the High-quality Multi-media Teaching System}

\section{$5.1 \quad$ Login module}

Students, teachers and system administrators can access the system through the login module, to engage in attendance, information modification and entering other modules. The design and implementation of the system login module can be accomplished by Java Web Service technology. Through the technology, students can obtain the list of courses and information released by administrators, select courses, and enter the main interface of the system for course learning. After login, teachers can publish information, update resources, maintain the system and use other functions.

\section{$5.2 \quad$ Video module}

The video module, mainly achieved by DirectShow technology, is employed for the completion of video capture, editing, transmission, playback and other functions. This technology has a low resource occupancy rate to keep the system operate fast. The sub-functions are independent of each other and designed to reach the goal of a high degree of modularity.

The implementation of the video module includes two processes: one is responsible for capture, encoding and transmission of videos and audios; the other is the process of receiving and playing videos. In the process of collection, DirectShow technology can divide the video stream into two streams, one for acquisition, and the other to be directly previewed and played in the system for convenient and timely viewing of piano performance. By receiving and separating video data, the acquiescent video playback hardware and resource library in the system will dock with each other to achieve user-friendly operation. Teachers can pre-store the required resources in the system; then, students can log on to watch related videos, complete pre-class preview and finish after-school consolidation according to their need.

\subsection{Audio module}

The audio module, composed of two sub-modules including recording and audio playback, is the essential feature of the high-quality multi-media teaching system. Teachers can record the playing demonstration to facilitate students' targeted learning. Meanwhile, students can also record training and performance audios, make full use of the system's specific high-quality feature to discover problems in performance, and have communication with different groups.

The audio playback module can play an important supporting role in teaching. Piano is quite expressive and pose higher requirements on sound volume and tone. Undeniably, high-quality audio player could meet these requirements of playing the piano. Teachers can pre-store audio resources in the audio module and classify them 
in accordance with learning difficulties and phased requirements. Students can log on the system, select multi-media resources that meet the specific training requirements, engage in self-learning, and give full play to the characteristics of high-quality multimedia.

\subsection{Interactive communication module}

Instrumental learning cannot be separated from the interaction between teachers and students and the exchange of feelings and experiences between students. The interactive module includes two modules, namely, online Q\&A and after-school exchange. Students can ask the teacher questions after logging on the system. The teacher can answer these questions through text exchange, or select targeted training resources for students to solve problems in learning by themselves. Besides, students can publish their experiences and latest works on the platform. Other students can browse questions and answers on the platform, and watch all types of works. The convenient interaction on the platform will enhance the teaching efficiency, and enable the teacher and students to make progress together. In addition, teachers can also release tasks on the communication platform. Obviously, both parties can achieve real-time communication through the system, to make up for the problems in teaching. (Figure 6)

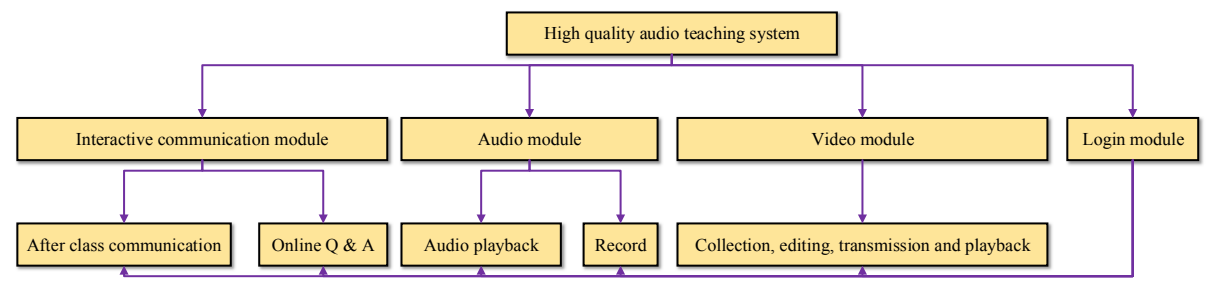

Fig. 6. High-quality multi-media teaching system

\section{Test of the Multi-media Teaching System}

To evaluate the teaching effect of the high-quality multi-media teaching system in the piano course, two class of Grade 2015 majoring in piano performance in Suzhou University in Anhui Province were selected as the experimental class and the control class to participate in a total of 64 hours of learning. The specific evaluation items are shown in Table 3.

The results of teaching effective evaluation show that the experimental class for which the high-quality multi-media teaching system is used was obvious different ( $p$ $<0.05$ ) with the control class in terms of classroom test, final evaluation and overall evaluation, but there was no obvious difference in staged evaluation. From the analysis of reasons, it could be known that the function of the high-quality multi-media teaching system is to enhance students' ability to play the piano. However, the evalua- 
tion content of staged evaluation focuses on theoretical knowledge and may lead to biased results.

Most of the students who participated in the survey were satisfied with the highquality multi-media teaching system. They believed that the system is closely related to the teaching of piano and could effectively improve the teaching efficiency. When first examining the reasons theoretically, it should be noticed that Meyer's theory emphasizes that the necessity for construction learners to build the knowledge learning mechanism by processing the materials presented by words and pictures. For example, the integration of course text with vivid, interesting images, high-quality, high-fidelity sound and other materials is conducive for students to construct new knowledge, thereby enhancing the learning effect; secondly, from the perspective of performance, the whole system has reached the predetermined design goals, and can meet the requirements of piano teaching on high quality and high level. Finally, technically speaking, with the combination of various hardware parts in the system, the music box can send the received audio signal to each speaker via special wireless communication. The proprietary synchronization protocol protects the complete synchronization between various speakers, to ensure the continuity of all teaching links to improve the teaching effect. At the same time, students' practice results would be improved substantially. In short, the results reveal that the high-quality multi-media teaching system can achieve the desired development goals.

Table 1. Diverse items to evaluate the high-quality multi-media teaching system

\begin{tabular}{|c|c|c|c|}
\hline \multirow{11}{*}{$\begin{array}{l}\text { Overall } \\
\text { evalua- } \\
\text { tion }\end{array}$} & $\begin{array}{c}\text { Evaluation method } \\
\text { (percentage) }\end{array}$ & Evaluation content (score) & Evaluation method (percentage) \\
\hline & \multirow{5}{*}{$\begin{array}{c}\text { Classroom test } \\
(20 \%)\end{array}$} & Basic knowledge (30 points) & \multirow{5}{*}{$\begin{array}{l}\text { Self-evaluation }(20 \%) \\
\text { In-group peer evaluation }(30 \%) \\
\text { Cross-group peer evaluation } \\
(10 \%) \\
\text { Teacher evaluation }(40 \%)\end{array}$} \\
\hline & & Playing skills (20 points) & \\
\hline & & Simple accompaniment (20 points) & \\
\hline & & Playing ability ( 20 points) & \\
\hline & & Extracurricular development (10 points) & \\
\hline & \multirow{2}{*}{$\begin{array}{c}\text { Staged evaluation } \\
(30 \%)\end{array}$} & Self-summary (20 points) & \multirow{2}{*}{ Performance evaluation } \\
\hline & & Theoretical test (40 points) & \\
\hline & \multirow{2}{*}{$\begin{array}{c}\text { Final evaluation } \\
(40 \%)\end{array}$} & Final test (60 points) & \multirow{2}{*}{ Comprehensive evaluation } \\
\hline & & Practice test (40 points) & \\
\hline & $\begin{array}{c}\text { Follow-up survey } \\
(10 \%)\end{array}$ & Satisfaction $(\%)$ & Results evaluation \\
\hline
\end{tabular}

Table 2. Comparison and evaluation of the teaching effect (score, $\mathrm{X} \pm \mathrm{SD}$ )

\begin{tabular}{cccccc}
\hline Group & $\begin{array}{c}\text { Classroom } \\
\text { test }\end{array}$ & $\begin{array}{c}\text { Staged evalua- } \\
\text { tion }\end{array}$ & $\begin{array}{c}\text { Final evalua- } \\
\text { tion }\end{array}$ & $\begin{array}{c}\text { Follow-up } \\
\text { survey }\end{array}$ & $\begin{array}{c}\text { Overall evalua- } \\
\text { tion }\end{array}$ \\
\hline $\begin{array}{c}\text { Control class } \\
\begin{array}{c}\text { Experimental } \\
\text { class }\end{array}\end{array}$ & $78.40 \pm 8.66$ & $72.52 \pm 9.20$ & $76.45 \pm 7.70$ & $72.95 \%$ & $75.79 \pm 6.55$ \\
& $84.94 \pm 6.38^{*}$ & $78.85 \pm 7.29$ & $81.48 \pm 5.81^{*}$ & $86.75 \%$ & $80.06 \pm 4.43^{*}$ \\
\hline
\end{tabular}

Note: when the experimental class is compared with the control group, ${ }^{*} \mathrm{p}<0.05$ 


\section{Conclusion}

Based on Meyer's theory of multi-media teaching, this paper designed and constructed the high-quality multi-media teaching system in combination with the actual demand of piano teaching. The design of hardware in the system, the design of modules in the system and the test of the system functions are all advanced in technology to some extent, in the hope of helping teachers to design the high-quality multi-media teaching software which accords with student's cognitive characteristics.

\section{$8 \quad$ References}

1. Mathew Myers, J., \& Halpin, R. "Teachers' attitudes and use of multimedia technology in the classroom: Constructivist-based professional development training for school districts," Journal of Computing in Teacher Education, vol. 18, no. 4, pp. 133-140, October 2002.

2. Yin, N. "Application of multi-media technology in piano teaching in colleges and universities," Information Technology \& Informatization, no. 8, pp. 86-87, August 2014.

3. Kwon, K.A., \& Byun, H.W. "Painterly Rendering Based on Piano Interface," International Journal of Multimedia and Ubiquitous Engineering, vol. 8, no. 6, pp. 269-278, June 2013. https://doi.org/10.14257/ijmue.2013.8.6.27

4. Costantini, G., Todisco, M., Perfetti, R. "NMF based Dictionary Learning for Automatic Transcription of Polyphonic Piano Music," Wseas Transactions on Signal Processing, vol. 9, no. 3, pp. 148-157, June 2013.

5. Cui, Q. "Research on digital piano teaching methods based network environment," Electronic Test, no. 23, pp. 168-168, December 2014.

6. Liu, Y.Y. "Application of computer music software in piano rhythm teaching and learning," Suiyue, vol. 2, no. 2, pp. 87-88, February 2011.

7. Ciaramella, A., Gianfico, M., Giunta, G. "Compressive sampling and adaptive dictionary learning for the packet loss recovery in audio multimedia streaming," Multimedia Tools \& Applications, pp. 1-18, November 2015. https://doi.org/10.1007/s11042-015-3002-x

8. Downs, E., Boyson, A.R., Alley, H., \& Bloom, N.R. "iPedagogy: Using multimedia learning theory to identify best practices for MP3 player use in higher education," Journal of Applied Communication Research, vol. 39, no. 2, pp. 184-200, April 2011. https://doi.org/10.1080/00909882.2011.556137

9. Jansen, B.J., Goodrum, A., Spink, A. "Searching for multimedia: analysis of audio, video and image Web queries," World Wide Web, vol. 3, no. 4, pp. 249-254, December 2000. https://doi.org/10.1023/A:1018743024123

10. Koroghlanian, C., Klein, J.D. "The effect of audio and animation in multimedia instruction," Journal of educational multimedia and hypermedia, vol. 13, no. 1, pp. 23, March 2004.

11. Tong, X., Lin, L.I., Yin, Z. "Web Map Publishing Technology Based on SVG and Java Applet," Computer Engineering, vol. 31, no. 11, pp. 62-64, June 2005. 
Paper-Design of Meyer's Theory-based High Quality Piano Multi-media System

\section{Author}

Pengfei Li is an teacher of Conservatory of Music, Suzhou University, Suzhou, China. His research interests include Piano Teaching and Multi-media System. (qqinyuan@yeah.net)

Submitted 03 December 2016. Published as resubmitted by the author 15 January 2017. 